\title{
Natural History Miscellany \\ Mother-Young Recognition in an Ungulate Hider Species: A Unidirectional Process
}

\author{
Marco V. G. Torriani, ${ }^{1,2, *}$ Elisabetta Vannoni, ${ }^{2, \dagger}$ and Alan G. McElligott ${ }^{2, *}$
}

1. Institute of Plant Sciences, Applied Entomology, Swiss Federal Institute of Technology (ETH), Schmelzbergstrasse 9, CH-8092, Zürich, Switzerland;

2. Zoologisches Institut, Universität Zürich, Winterthurerstrasse 190, CH-8057, Zürich, Switzerland

Submitted December 14, 2005; Accepted May 9, 2006;

Electronically published August 7, 2006

Online enhancements: sound files.

ABSTRACT: Parent-offspring recognition is usually crucial for survival of young. In mammals, olfaction often only permits identification at short range, and vocalizations are important at longer distances. Following and hiding antipredator strategies found in newborn mammals may also affect parental recognition mechanisms. We investigated mother-offspring recognition in fallow deer, an ungulate hider species. We analyzed the structure of adult female and fawn contact calls to determine whether they are individually distinctive and tested for mother-offspring recognition. Only females (and not fawns) have individualized vocalizations, with the fundamental frequency as the most distinctive parameter. Playback experiments showed that fawns can distinguish the calls of their mothers from those of other females, but mothers could not discriminate their own and alien fawn calls. Thus, the vocal identification process is unidirectional. In followers, mother-offspring acoustic recognition is mutual, and therefore the different antipredator strategies of newborn mammals may have shaped the modalities of parent-offspring acoustic recognition.

Keywords: fallow deer, following, hiding, parent-offspring recognition, ungulate, vocal communication.

Sophisticated parent-offspring recognition is essential when parental investment is large and in colony- or herd-

\footnotetext{
* E-mail: marco.torriani@ipw.agrl.ethz.ch.

† E-mail: evannoni@zool.unizh.ch.

¥ Corresponding author; e-mail: amcellig1@yahoo.ie.
}

Am. Nat. 2006. Vol. 168, pp. 412-420. (c) 2006 by The University of Chicago. 0003-0147/2006/16803-41493\$15.00. All rights reserved. living animals where the potential exists for identification errors (Trivers 1972; Trillmich 1996; Jouventin and Aubin 2002). The most important component of parental care in mammals is lactation (Pond 1977; Gittleman and Thompson 1988). Females usually display selective maternal investment by restricting care to their own offspring and rejecting others, although milk stealing and/or allosuckling can also occur (Roulin 2002). The ability of mothers and offspring to recognize each other is therefore crucial to avoid misdirected maternal investment and to ensure survival of young.

Two main strategies for avoiding predators in the first weeks of life have evolved in newborn ungulates and macropods: following and hiding (Fisher et al. 2002; Caro 2005). Follower young are mobile soon after birth and therefore rely on fleeing and maternal and group defense to avoid predation. Hider young spend most of their time hidden in vegetation to avoid detection by potential predators. The follower strategy evolved in species that live in open habitats, whereas hiders live in habitats providing cover (Fisher et al. 2002). It is possible that these two widely differing strategies may also have affected the vocal recognition process of mothers and offspring because of the large differences in the way mothers and offspring of follower and hider species interact during the first weeks of life.

The recognition process between ungulate mothers and their offspring mainly involves olfaction and audition (Searby and Jouventin 2003). Olfaction supports recognition only at short range and is used by mothers for a final check of offspring identity before allowing suckling. Acoustic signals are efficient over both short and long distances, and therefore vocal communication appears to be a key factor for mother-offspring recognition (Searby and Jouventin 2003). Vocal communication is particularly important for ungulate hider species because mothers and offspring rely on calling for reunions to occur when offspring are hidden.

There is already some evidence to suggest that motheroffspring recognition varies in relation to different anti- 


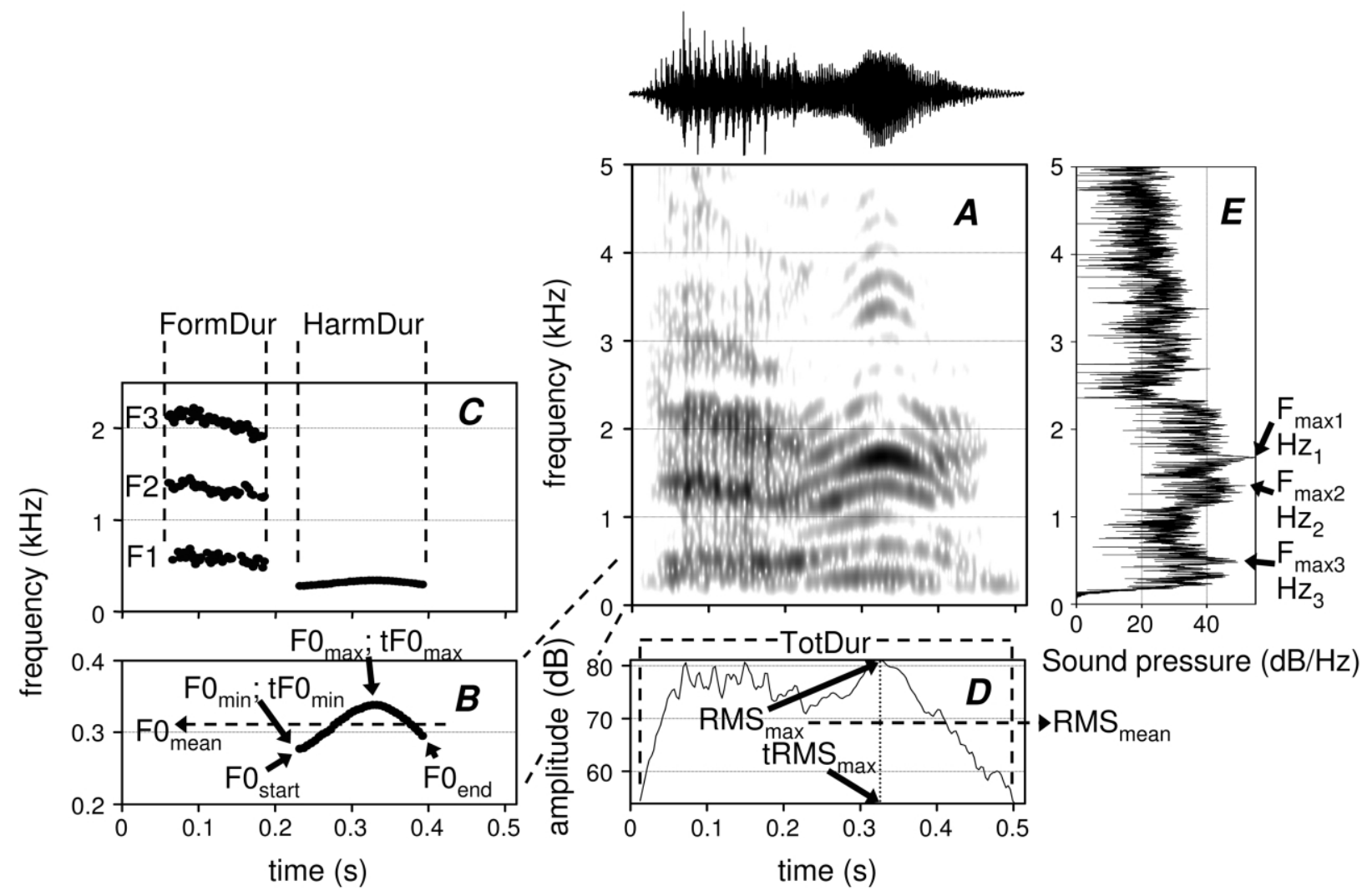

Figure 1: Analysis method of the acoustic parameters of adult female and fallow deer fawn contact calls, using an example of an adult female call. $A$, Spectrogram of the call (window length $=0.01 \mathrm{~s}$, frequency resolution $=60 \mathrm{~Hz}$, Gaussian window shape). $B$, Fundamental frequency profile. $C$, Formant pattern, estimated using linear predictive coding. $D$, Intensity contour. $E$, Average power spectrum, showing the energy distribution among frequencies.

predatory strategies of the offspring. In follower species such as domestic sheep (Ovis aries; Shillito-Walser et al. 1981; Searby and Jouventin 2003) and reindeer (Rangifer tarandus; Espmark 1971, 1974), mothers and young are capable of recognizing each other using contact calls. Less is known about hider species; in domestic goats (Capra hircus; Ruiz-Miranda et al. 1993) and red deer (Cervus elaphus; Vaňková et al. 1997), adult females have individually distinctive contact calls that can potentially allow individual discrimination. However, it is not known if adult females of hider species are able to identify their offspring using contact calls, or if offspring can recognize their mothers using contact calls.

We investigated mother-offspring acoustic recognition in fallow deer (Dama dama), an ungulate hider species. Young fallow deer lie concealed and silent in vegetation, and separated from other conspecifics for their first 2-3 weeks of life. Mothers spend most of the time away from the place where their fawns are hidden and return inter- mittently to feed them. Females usually do not know the exact locations of offspring hiding places. Therefore, a mother first approaches the approximate location and vocalizes, and then the fawn joins the mother for suckling. After the initial hiding phase, fallow deer fawns follow their mothers in large mixed herds of females and other fawns, and fawns also vocalize more frequently (Gilbert 1968; Braza and San Josè 1988).

First, we analyzed the acoustic structure of adult female and fawn contact calls to determine whether they were individually distinctive (Reby and McComb 2003; Searby and Jouventin 2003). Fallow deer fawns are sexually size dimorphic at birth, and males also grow faster than females (Birgersson and Ekvall 1997). Therefore, we also examined age and sex differences in fawn contact calls because these factors could affect the potential for recognition. Using playbacks, we then experimentally tested the capabilities of mothers and fawns to recognize each other's vocalizations. 


\section{Methods \\ Study Sites and Animals}

This study was conducted from June 4 to September 1, 2004, using two herds of European fallow deer on farms. These herds consisted of 21 adult females and 20 fawns located in Oberembrach (Canton Zurich, Switzerland) and 13 adult females and 6 fawns in Paspels (Canton Graubünden, Switzerland). All fawns and 30 females were tagged and therefore individually identifiable. Tagging of deer is carried out routinely by the owners each year and was not done for the purposes of this study. Females that had lost their tags $(n=4)$ were easily recognized using a combination of coat pattern and the individually distinctive tear patterns of the ears following tag loss. All fawns were born between June 11 and 26. Adult females ranged in age from 2 to 10 years, but the age of individuals was not known.

\section{Recording Procedure and Signal Acquisition}

Calls were recorded according to Vannoni et al. (2005). We used a Praat 4.3 DSP package (P. Boersma and D. Weenink, University of Amsterdam, The Netherlands) to generate spectrograms (fig. $1 A$, Fast Fourier Transform [FFT] method, window length $=0.01 \mathrm{~s}$, time step $=$ 1,000 , frequency step $=250$, frequency resolution $=60$ $\mathrm{Hz}$, Gaussian window shape, dynamic range $=35 \mathrm{~dB}$ ) of the vocalizations. Each call was visually inspected; vocalizations with high levels of background noise were rejected, and therefore good quality recordings were not available for all animals in each herd. We finally analyzed 574 calls from 12 fawns (13-112 calls for each individual) and 487 calls from 14 adult females (14-78 calls for each individual).

\section{Acoustic Analyses}

Time-varying numerical representations of the fundamental frequency (F0) for each call were produced using a pitch analysis (Sound: To Pitch (ac) command, time step $=0.001 \mathrm{~s}$, Gaussian window) based on an autocorrelation algorithm associated with filtration of the signal ( pitch floor $=350 \mathrm{~Hz}$, pitch ceiling $=900 \mathrm{~Hz}$ for fawn calls; pitch floor $=150 \mathrm{~Hz}$, pitch ceiling $=600 \mathrm{~Hz}$ for adult female calls) as described in Boersma (1993). We then used these frequency contours (fig. $1 B$ ) to measure the following F0 and temporal parameters: F0 mean $\left(\mathrm{F} 0_{\text {mean }}\right)$, F0 initial $\left(\mathrm{F}_{\text {start }}\right)$, F0 final $\left(\mathrm{F}_{\text {end }}\right), \mathrm{F} 0$ minimum $\left(\mathrm{F}_{\text {min }}\right)$, $\mathrm{F} 0$ maximum $\left(\mathrm{F} 0_{\max }\right)$, time of $\mathrm{F} 0$ minimum $\left(t \mathrm{~F}_{\text {min }}\right)$, time of $\mathrm{F} 0$ maximum $\left(t \mathrm{~F} 0_{\text {max }}\right)$, total duration (TotDur) of the calls of fawns, and duration of the harmonic part (HarmDur) of the calls of adult females.

We used linear predictive coding analysis (Sound: To Formant [burg] command, time step $=0.001 \mathrm{~s}$, maximum number of formants $=3$, maximum formant $=$ $1,800-2,600 \mathrm{~Hz}$, window length $=0.025 \mathrm{~s}$, preemphasis from $30 \mathrm{~Hz}$; see Press et al. 1992) to estimate the formant frequencies (vocal tract resonances, fig. 1C) of adult female calls. We extracted the mean frequency of the first three formants (F1, F2, and F3) and measured the duration of the formant part (FormDur) for each call.

Using the intensity contour (fig. $1 D$, Sound: To Intensity command, minimum pitch $=350 \mathrm{~Hz}$ for fawn calls and $150 \mathrm{~Hz}$ for adult female calls, time step = auto) of the calls, we measured the maximum intensity $\left(\mathrm{RMS}_{\max }\right)$, the mean intensity $\left(\mathrm{RMS}_{\text {mean }}\right)$, and the time when highest am-
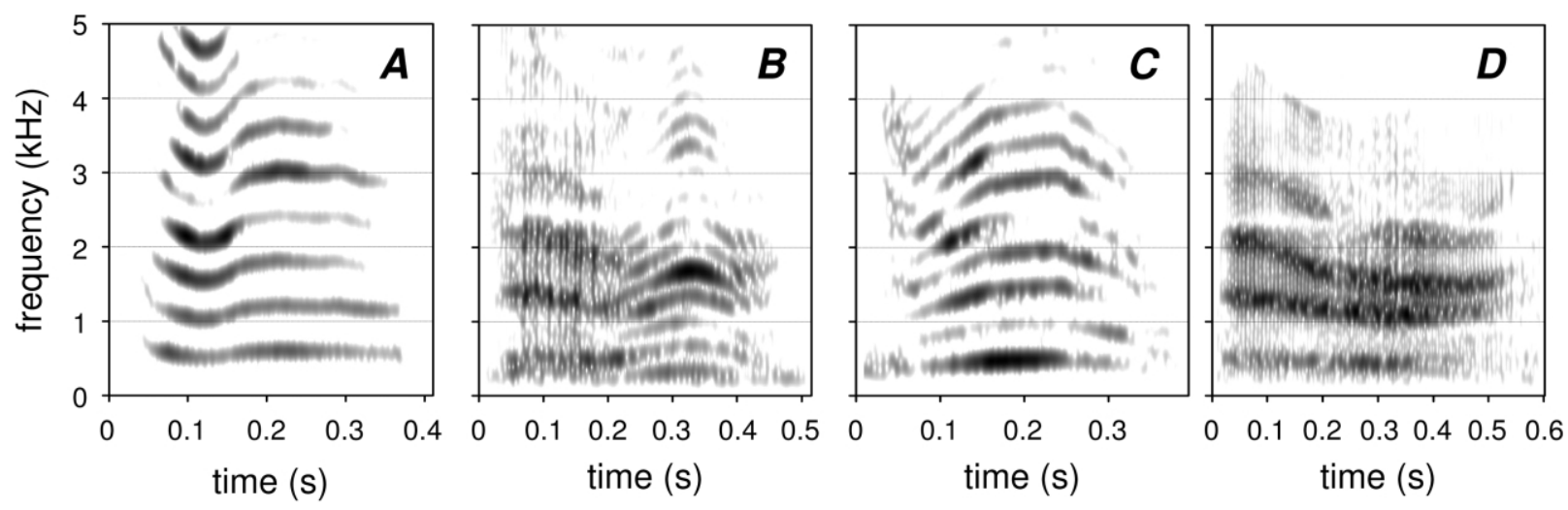

Figure 2: Narrow band spectrograms (window length $=0.01 \mathrm{~s}$, frequency resolution $=60 \mathrm{~Hz}$, Gaussian window shape) of typical contact calls of fawns with well-defined harmonics $(A)$ and of adult females: call with a first noisy part and a second part with harmonic structure $(B)$, tonal call $(C)$; and noisy call $(D)$. Sound files with examples of the four types of calls are available in the online edition of the American Naturalist. 
Table 1: Descriptive statistics for the acoustic parameters of fallow deer fawn contact calls divided according to age

\begin{tabular}{|c|c|c|c|}
\hline $\begin{array}{l}\text { Parameter and } \\
\text { variable }\end{array}$ & $\begin{array}{c}\text { Age class } 1 \\
(\text { mean } \pm \mathrm{SD})\end{array}$ & $\begin{array}{c}\text { Age class } 2 \\
(\text { mean } \pm \mathrm{SD})\end{array}$ & $P$ \\
\hline \multicolumn{4}{|l|}{ Duration (s): } \\
\hline TotDur & $.15 \pm .04$ & $.20 \pm .02$ & $<.001$ \\
\hline \multicolumn{4}{|l|}{ Frequency $(\mathrm{Hz})$ : } \\
\hline $\mathrm{F}_{\text {start }}$ & $650 \pm 67$ & $581 \pm 65$ & $<.001$ \\
\hline $\mathrm{F}_{\text {end }}$ & $638 \pm 50$ & $579 \pm 39$ & $<.001$ \\
\hline $\mathrm{F} 0_{\text {min }}$ & $598 \pm 64$ & $540 \pm 51$ & $<.001$ \\
\hline $\mathrm{F}_{\text {max }}$ & $699 \pm 52$ & $656 \pm 43$ & $<.001$ \\
\hline $\mathrm{F} 0_{\text {mean }}$ & $653 \pm 57$ & $611 \pm 46$ & $<.001$ \\
\hline \multicolumn{4}{|c|}{ Modulation (\%): } \\
\hline$t \mathrm{~F} 0_{\text {min }}$ & $47 \pm 30$ & $50 \pm 18$ & .425 \\
\hline$t \mathrm{~F} 0_{\max }$ & $47 \pm 26$ & $52 \pm 15$ & .084 \\
\hline$t \mathrm{RMS}_{\max }$ & $37 \pm 18$ & $38 \pm 9$ & .328 \\
\hline \multicolumn{4}{|l|}{ Intensity: } \\
\hline $\mathrm{RMS}_{\text {ratio }}$ & $1.07 \pm .02$ & $1.08 \pm .01$ & .020 \\
\hline \multicolumn{4}{|l|}{ Energy peaks: } \\
\hline $\mathrm{F}_{\max 1}$ & F0 & F0 & .480 \\
\hline $\mathrm{F}_{\max 2}$ & $\mathrm{H} 1$ & $\mathrm{H} 1$ & .260 \\
\hline $\mathrm{F}_{\max 3}$ & H3 & $\mathrm{H} 4$ & .550 \\
\hline
\end{tabular}

Note: Age class 1, 28-52 days; age class 2, 53-78 days. Age differences were examined using a general linear mixed model analysis. Measurements of the energy distribution $\left(\mathrm{F}_{\max 1}, \mathrm{~F}_{\max 2}\right.$, and $\left.\mathrm{F}_{\max 3}\right)$ were tested using Wilcoxon signedranks test.

plitude peak occurs $\left(t \mathrm{RMS}_{\max }\right)$. Temporal parameters such as $t \mathrm{RMS}_{\max }$, FormDur, and HarmDur were divided by TotDur of the calls to express them in a relative way. Similarly, we also divided the temporal parameters related to F0 by HarmDur. Because the measurement of RMS ${ }_{\max }$ and $\mathrm{RMS}_{\text {mean }}$ vary according to the distance between the calling animal and the microphone, and this distance was not always the same, we calculated the additional variable $\mathrm{RMS}_{\text {max }} / \mathrm{RMS}_{\text {mean }}\left(\mathrm{RMS}_{\text {ratio }}\right)$. Moreover, we used the intensity contour to calculate the total duration (TotDur) of the adult female calls.

For each call, we displayed average power spectra (fig. $1 E$; Sound: To Spectrum command, FFT) to quantify the distribution of the energy among frequencies. We identified the first three bands with energy peak $\left(\mathrm{F}_{\max 1}, \mathrm{~F}_{\max 2}\right.$, and $\left.\mathrm{F}_{\max 3}\right)$ and measured their relative frequencies $\left(\mathrm{Hz}_{1}\right.$, $\mathrm{Hz}_{2}$ and $\mathrm{Hz}_{3}$ ). Then we calculated the percentage of occurrence of F0 of each harmonic and of each formant as the first three frequencies of highest amplitude.

\section{Playback Experiments}

We carried out playback experiments on 12 mother-fawn (6 males, 6 females) pairs that belonged to the Canton Zurich herd. The fawns were aged 52-73 days during playbacks, and therefore the hiding phase was over and they had been accompanying their mothers for at least 30 days.
Each playback was performed when mothers and fawns had lost contact within the enclosure ( $\sim 4$ ha) and approximately $2 \mathrm{~h}$ had passed since the last suckling, and therefore all animals were motivated to respond. We observed the herd to determine when sucklings occurred. Sequences were played when mothers or fawns were lying down and were $15-50 \mathrm{~m}$ from the speaker. Calls were played back directly from a laptop computer that was connected to a battery-powered loudspeaker (Sound Projections Sound Machine SM-2, frequency response $65 \mathrm{~Hz}-$ $16 \mathrm{kHz}$ ). Based on the observed natural occurrence of the reunion processes between mothers and their fawns, we did not perform more than two playback experiments/day. We tested all the fawns ( 6 females, 6 males) and half of the mothers twice during the study period, with 2 weeks between the two sessions to avoid habituation (McGregor et al. 1992). The remaining mothers were tested once. During playbacks, the observers and loudspeaker were concealed from view.

Each playback session consisted of two 30-s sequences played in random order: calls of own mother or own young and calls of an alien mother or an alien fawn. Playback sequences were separated by 2 -min silence because this time interval allowed the animals to return to their previous activity before the next sequence was played. Each sequence was composed of 24 calls from the same individual, of which a minimum of 12 were different calls (for both treatments) to avoid pseudoreplication (Kroodsma et al. 2001; Wiley 2003). This number of calls represents a natural calling rate $(48 \mathrm{calls} / \mathrm{min} ; \mathrm{M}$. V. G. Torriani and A. G. McElligott, unpublished data). Because the call structure was likely to change as fawns grew, only calls recorded within 1 week before the experiments were included in the sequences played back to the mothers.

We used two cameras (Sony digital video camera, DCRTVR 50E) to film the responses of two fawns (own and alien) or two mothers (own and alien) simultaneously, from 2 min before until 2 min after each playback. The reactions of the tested animals were classified as negative (0) if no behavioral change was detected and positive (1) if one of the following behaviors occurred: head turns with ears oriented toward the loudspeaker, call in reply, or movement toward the loudspeaker. When playbacks elicited the reunion between the mother and fawn $(n=6)$, the session was interrupted, and the remaining sequence was not used in the statistical analysis. This explains the small sample size difference in the results of our playbacks.

\section{Statistical Analysis}

We investigated age and sex differences in fawn calls using a general linear mixed model (GLMM) procedure fitted with residual maximum likelihood estimation (REML, lme 
function; Venables and Ripley 2002). Individual identity was fitted as a random term, and age and sex were fitted as fixed effects. We considered two age classes of the same length (28-52 and 53-78 days old). We performed a multivariate GLMM including the F0-related parameters and a univariate GLMM for all the measured acoustic parameters. When the interaction between age and sex was not significant, we ran the analysis again, excluding the interaction term (Engqvist 2005). This analysis was performed in $\mathrm{R}$ for Windows version 2.0.1 (R Development Core Team 2004) with the packages "nlme" (Pinheiro et al. 2004) and "MASS" (Venables and Ripley 2002). All the other statistical analyses were performed using SPSS 11.5. Because $\mathrm{F}_{\max 1}, \mathrm{~F}_{\max 2}$, and $\mathrm{F}_{\max 3}$ were ordinal measurements, for these parameters, age differences were tested using the Wilcoxon signed-ranks test and sex differences were tested using the Mann-Whitney $U$-test.

We used principal component analysis (PCA) to reduce the original data set of all measured variables of adult female and fawn calls to a smaller set of uncorrelated variables, retaining as much information as possible. The key variables that explained most of the variance were then included in the discriminant function analysis (DFA). With this method, we investigated whether there were differences that would allow discrimination between individuals and which acoustic parameter was most likely to code for individual identity. We separately analyzed 115 calls from
12 adult females (5-12 each, randomly selected from different recordings taken during July and August) and 140 calls of 12 fawns (8-12 each, randomly selected within the second age class).

In order to test the influence of the playback sequences on the behavior of mothers and fawns, we used a binary logistic regression model with the binary variable "response" or "no response." We then performed an ANOVA to investigate any difference in the duration of the positive reactions. All tests were two tailed and were considered significant if $P<.05$. Means were given with standard deviation $( \pm S D)$.

\section{Results \\ Description of Calls}

Contact calls of fawns were tonal (fig. $2 A$ ); their F0 ranged from 374.4 to $863.0 \mathrm{~Hz}$ (mean $=632.1 \pm 54.9 \mathrm{~Hz}$ ) and their duration from 0.05 to $0.38 \mathrm{~s}$ (mean $=0.17 \pm 0.04$ s). Adult females emitted three different calls: $69.3 \%$ of the recorded calls were composed of a noisy part first and a second part with harmonic structure (fig. 2B), 24.7\% were tonal (fig. $2 C$ ), and $10.7 \%$ were completely noisy (fig. $2 D$ ). Calls of adult females were characterized by low F0 that varied from 152.7 to $579.1 \mathrm{~Hz}$ (mean $=365.0 \pm$ $85.7 \mathrm{~Hz}$ ). The mean frequencies of the first three formants

Table 2: Descriptive statistics for the acoustic parameters of fallow deer fawns contact calls divided according to sex and age

\begin{tabular}{|c|c|c|c|c|c|}
\hline \multirow[b]{2}{*}{ Parameter } & \multicolumn{2}{|c|}{$\begin{array}{c}\text { Age class } 1 \\
(\text { mean } \pm \mathrm{SD})\end{array}$} & \multicolumn{2}{|c|}{$\begin{array}{c}\text { Age class } 2 \\
(\text { mean } \pm S D)\end{array}$} & \multirow[b]{2}{*}{$P$} \\
\hline & Females & Males & Females & Males & \\
\hline \multicolumn{6}{|c|}{ Duration (s): } \\
\hline TotDur & $.14 \pm .06$ & $.15 \pm .03$ & $.19 \pm .02$ & $.20 \pm .02$ & .101 \\
\hline \multicolumn{6}{|c|}{ Frequency $(\mathrm{Hz})$ : } \\
\hline $\mathrm{F}_{\text {start }}$ & $665 \pm 83$ & $634 \pm 49$ & $610 \pm 38$ & $552 \pm 77$ & .035 \\
\hline $\mathrm{F} 0_{\text {end }}$ & $639 \pm 65$ & $636 \pm 36$ & $597 \pm 29$ & $560 \pm 41$ & .034 \\
\hline $\mathrm{F} 0_{\min }$ & $601 \pm 90$ & $596 \pm 30$ & $565 \pm 31$ & $516 \pm 58$ & .009 \\
\hline $\mathrm{F} 0_{\max }$ & $710 \pm 62$ & $689 \pm 44$ & $671 \pm 35$ & $64.9 \pm 48.7$ & .371 \\
\hline $\mathrm{F} 0_{\text {mean }}$ & $658 \pm 74$ & $649 \pm 41$ & $628 \pm 33$ & $593 \pm 53$ & .057 \\
\hline \multicolumn{6}{|c|}{ Modulation (\%): } \\
\hline$t \mathrm{~F} 0_{\min }$ & $57 \pm 37$ & $39 \pm 24$ & $58 \pm 16$ & $45 \pm 22$ & .272 \\
\hline$t \mathrm{~F} 0_{\max }$ & $45 \pm 38$ & $52 \pm 12$ & $50 \pm 14$ & $57 \pm 16$ & .504 \\
\hline$t \mathrm{RMS}_{\max }$ & $42 \pm 27$ & $35 \pm 5$ & $37 \pm 11$ & $41 \pm 8$ & .405 \\
\hline \multicolumn{6}{|l|}{ Intensity: } \\
\hline $\mathrm{RMS}_{\text {ratio }}$ & $1.07 \pm .04$ & $1.07 \pm .01$ & $1.07 \pm .00$ & $1.08 \pm .02$ & .255 \\
\hline \multicolumn{6}{|c|}{ Energy peaks: } \\
\hline $\mathrm{F}_{\max 1}$ & F0 & H1 & F0 & F0 & .291 \\
\hline $\mathrm{F}_{\max 2}$ & $\mathrm{H} 2$ & $\mathrm{H} 1$ & $\mathrm{H} 1$ & F0 & .478 \\
\hline $\mathrm{F}_{\max 3}$ & F0 & $\mathrm{H} 3$ & $\mathrm{H} 4$ & $\mathrm{H} 4$ & .514 \\
\hline
\end{tabular}

Note: Age class 1, 28-52 days; age class 2, 53-78 days. Sex differences were examined using a general linear mixed model analysis. Measurements of the energy distribution $\left(\mathrm{F}_{\max }, \mathrm{F}_{\max 2}\right.$, and $\left.\mathrm{F}_{\max 3}\right)$ were tested using Mann-Whitney $U$-test. 

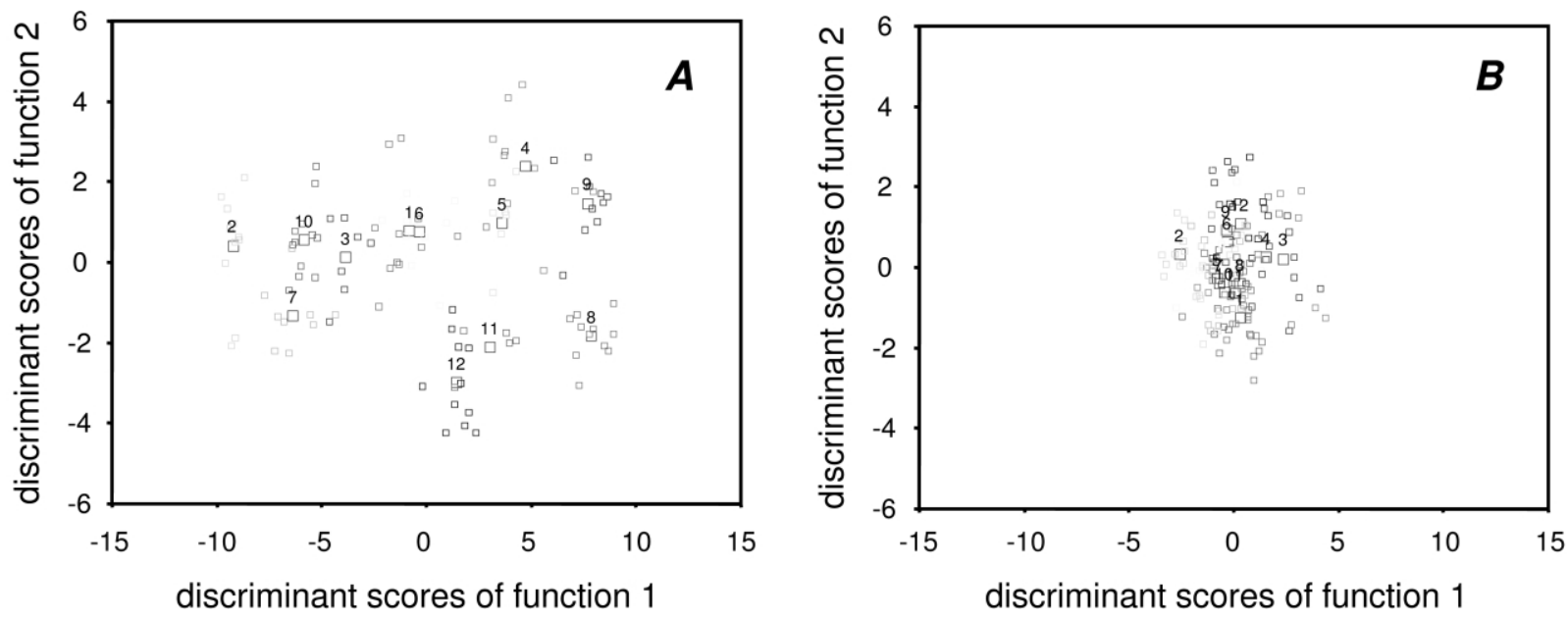

Figure 3: Discriminant function scores of adult female $(A ; n=12)$ and fawn $(B ; n=12)$ calls. Squares of the same color represent calls of the same individual.

were $539.0 \pm 71.8 \mathrm{~Hz}$ for $\mathrm{F} 1,1,296.6 \pm 66.9 \mathrm{~Hz}$ for $\mathrm{F} 2$, and $2,009.5 \pm 166.0 \mathrm{~Hz}$ for $\mathrm{F} 3$. The call duration ranged from 0.14 to $0.62 \mathrm{~s}$ (mean $=0.35 \pm 0.08 \mathrm{~s}$ ).

\section{Age and Sex Differences in Fawns}

We found that as the fawns aged, the F0-related parameters became significantly lower (multivariate GLMM: $F=$ 231.39, $\mathrm{df}=1,560, P<.001$ ), and the duration of the calls became significantly longer (univariate GLMM: $F=$ 66.68 , df $=1,560, P<.001$; table 1 ). Intensity (RMS ratio) was significantly lower in the first than in the second age class (univariate GLMM: $F=5.41, \mathrm{df}=1,560, \quad P=$ .020). Parameters related to F0 modulation, intensity modulation, and energy distribution were not different in the two age classes (table 1). The F0-related parameters were significantly lower in males than in females (multivariate GLMM: $F=5.08, \mathrm{df}=1,560, P=.025)$. In addition, there was no effect of sex on any of the other measured parameters (table 2).

\section{Individuality of Calls}

We first performed a PCA on all the measured acoustic parameters for adult female and fawn calls separately. Based on the results of the PCA, we grouped all the measured parameters into four independent categories: duration, frequencies, time modulation, and energy. We then ran a second PCA within each category, and the comparison of the outcomes of both PCAs resulted in a final selection of four acoustic parameters that were included in the DFA: $F 0_{\text {mean }}$, TotDur, $t \mathrm{~F} 0_{\text {min }}$, and $t \mathrm{RMS}_{\max }$ for the calls of fawns; $\mathrm{F}_{\text {mean }}, \mathrm{F} 3$, TotDur, and $t \mathrm{FO}_{\text {min }}$ for the calls of adult females.

Cross-validated DFA classified $81.7 \%$ of the adult female contact calls correctly, whereas only $32.1 \%$ of the fawn contact calls were correctly assigned (fig. 3 ). The $\mathrm{F} 0_{\text {mean }}$ was the most individually distinctive parameter in both adult female and fawn calls, explaining $53.7 \%$ and $27.1 \%$ of the variability, respectively. In adult female calls, the mean frequency of the third formant alone explained $28.0 \%$ of the variance, the call duration alone $22.2 \%$, and the time of F0 minimum alone $18.4 \%$.

\section{Playback Experiments}

Fawns reacted significantly more often to calls of their mothers than to calls of alien females (fig. $4 A ; \chi^{2}=$ 5.70, $\mathrm{df}=1,42, P=.02)$. Mothers reacted similarly to calls of their fawns and calls of alien fawns (fig. 4B; $\left.\chi^{2}=0.49, \mathrm{df}=1,32, P=.48\right)$. The interaction term for "receiver" (mother/fawn) and "playback type" (alien/own) was also significant $\left(\chi^{2}=6.08, \mathrm{df}=1,74, P=.01\right)$. Thus, fawns could discriminate between own and alien mother contact calls, whereas mothers could not discriminate between own and alien fawns. We did not find significant differences in the duration of fawn reactions to own or alien mothers (ANOVA: $F=0.77$, df $=1,23$, $P=.40$ ), or in the duration of mother reactions to own or alien fawns (ANOVA: $F=3.23$, df $=1,14, P=.10$ ). 


\section{Discussion}

Our results show that only adult female fallow deer (and not fawns) have individualized contact calls and the fundamental frequency was the most individually distinctive parameter. Playback experiments confirmed that these calls were used by fawns for maternal recognition because they reacted more often to the calls of their own mothers than to the calls of alien females. We found that mothers did not recognize the contact calls of their own fawns. Our findings show that in an ungulate hider species, fawns are responsible for mother-offspring acoustic recognition. It is crucial for fawns to correctly recognize their mothers in order to receive milk, and to avoid leaving the hiding place in response to a female that is not its mother, during the early phase of life. At the same time, females gain direct fitness benefits because the production of individually distinctive calls allows the reunion process, and therefore survival of their offspring, to occur. This one-way recognition system persists into the age at which fawns join adults in the herd, as this is the age at which we carried out the playbacks. Studies of follower ungulates such as sheep (Searby and Jouventin 2003) and reindeer (Espmark 1971, 1974) found that both mother and offspring are able to recognize each other based on their contact calls. Together, these results suggest that the evolution of different antipredator strategies in young ungulates (following, hiding) also shaped the modalities of acoustic recognition between mothers and young. This appears to be independent of phylogenesis, because although fallow deer and reindeer are more closely related than reindeer and sheep, the mother-offspring recognition of the latter two species is more similar.

The acoustic analysis showed that adult female calls were individually distinctive, with the fundamental frequency as the most distinctive parameter and temporal parameters less distinctive. Therefore, the acoustic recognition of fallow deer mothers by fawns is likely to be similar to that found in sheep (Searby and Jouventin 2003). The fundamental frequency is related to the length and thickness of the vocal folds in the larynx, and therefore, it is not surprising that this acoustic cue is highly individualized (Titze 1994; Charrier et al. 2002). We found that adult females produced three types of calls: tonal calls with a relatively high fundamental frequency, calls with a first noisy part and a second part with harmonic structure, and low-pitched noisy calls. In a noisy adult female call (fig. $2 D)$, the formant frequencies decreased slightly during the call, thereby indicating a vocal tract elongation caused by a small lowering of the larynx (Fitch 1997; McElligott et al. 2006).

Fawn contact calls were not individually distinctive, and as the fawns grew, their calls became longer and deeper as the vocal folds lengthened and thickened and the larynx increased in size (Titze 1994). The changing call structure is most likely related to the lack of individuality, and together, these factors make recognition difficult. In fallow deer, males are born larger and grow faster than females, and these differences are reflected in the lower fundamental frequency related parameters in males (Birgersson and Ekvall 1997; this study). Our findings are consistent
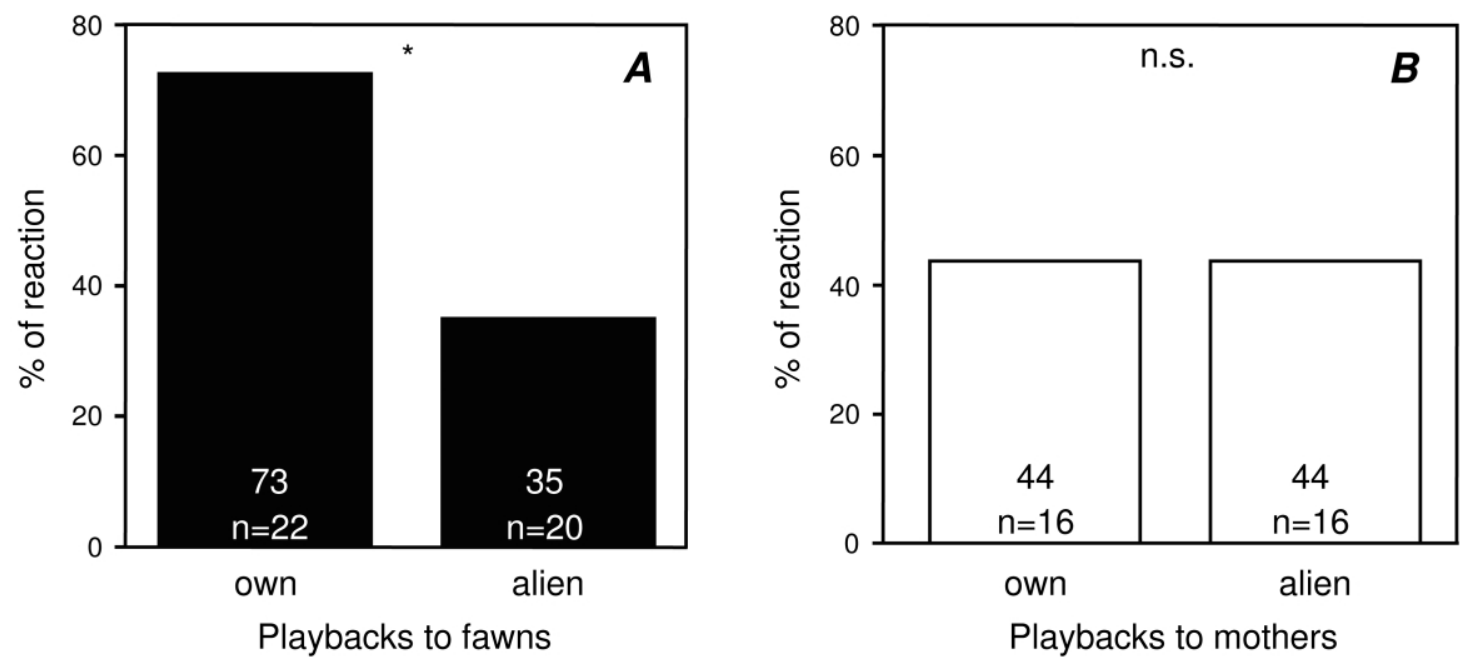

Figure 4: Results of playbacks of own and alien calls to $(A)$ fawns and $(B)$ mothers: the percentage of reactions to calls of the own mother or fawn and to calls of an alien mother or fawn. Comparisons between responses to own and alien calls were carried out using binary logistic regressions. Significance is shown above the bars: asterisk indicates $P<.05$; NS indicates not significant. 
with those for red deer stags, in which the mean and maximum fundamental frequencies are higher on average in subadults than in adults (Reby and McComb 2003).

Our playbacks showed that fawns were able to discriminate between mother calls and those of alien females. However, fawns also sometimes reacted positively to calls of alien females. After the hiding phase, both allosucking and the stealing of milk from alien mothers are common in fallow deer (Birgersson et al. 1991; Pélabon et al. 1998; Roulin 2002). Therefore, it is not surprising that fawns sometimes react to the contact calls of alien mothers if it indicates that a suckling will occur because fawns only attempt to steal milk from alien mothers after they have begun to nurse their own fawns (Ekvall 1998). Mothers try to avoid misdirected maternal investment by checking the identity of their fawns using olfaction (Ekvall 1998). Fawns did not always respond to own mother calls. The presence of a visual cue (e.g., an approaching mother) could also act as a stimulus for the fawns and perhaps enhance the positive reactions to own mother calls (Shillito-Walser et al. 1981).

The playbacks to mothers showed that they did not recognize their own fawns using contact calls. During the hiding phase, the mothers call the fawns to initiate the reunion process, whereas fawns are largely silent (Gilbert 1968; Braza and San Josè 1988). There is little opportunity for mothers to learn the calls of their offspring because of the limited periods that they spend together. Moreover, our results have shown that there is little individuality in the calls of fawns, even at the older ages, when they have joined adults in a herd and they vocalize more frequently. It is also unlikely that the results of our playbacks to mothers could have been due to mothers ignoring the calls of their own fawns, because they were carried out when fawns were 7-10 weeks old. Females do not stop nursing their young until they are several months older than this (Birgersson and Ekvall 1997). Our results suggest that the environmental conditions (closed vs. open habitats) that influence predator avoidance strategies (hiding/following) in turn affect parent-offspring contact and recognition mechanisms and the development of the vocal apparatus in young mammals. In terms of the vocal apparatus, we mean the ability or inability (in the case of ungulate hiding young) to produce individually distinct vocalizations.

The vocal characteristics of fawns change as they grow, and therefore, it is crucial for fawns to recognize their mothers from the more stable characteristics of their adult calls. The complex mutual vocal recognition systems found in mammals that live in large mixed groups of adults and offspring (Insley 2000, 2001; Charrier et al. 2001, 2002; Searby and Jouventin 2003) may have evolved because of the potential for identity confusion at early ages in these species. In most other mammals, including hiding un- gulates, a less complex vocal recognition system along with olfaction seems to be enough to ensure that mothers and offspring can recognize one another effectively and communicate. Future studies of parent-offspring vocal recognition in mammals and other species should focus on determining whether there are asymmetries in recognition that depend on the dynamics of how parents interact with offspring in early life.

\section{Acknowledgments}

We thank M. Buchmann (Schweizerische Vereinigung der Hirschhalter) and M. Giacometti (Wildvet projects) for their help finding cooperative farmers, and we thank R. Bischoff, E. Tanno (http://www.damwild.ch), and S. Meier and P. Meier for access to their deer. Special thanks to M. Sautter and O. Sonzogni for help in the field; additional field assistance was given by M. Camani, P. Decristophoris, M. Lichtsteiner, R. Rieser, and E. Sonzogni. We thank L. Bartoš, W. Blanckenhorn, B. König, H. Kunc, and M. Manser for advice, and we thank G. Dell'Omo and the anonymous reviewers for helpful comments on the manuscript. We acknowledge the financial support of the Forschungskommission der Universität Zürich (E.V.) and the HelenBieber Fonds for equipment.

\section{Literature Cited}

Birgersson, B., and K. Ekvall. 1997. Early growth in male and female fallow deer fawns. Behavioral Ecology 8:493-499.

Birgersson, B., K. Ekvall, and H. Temrin. 1991. Allosuckling in fallow deer, Dama dama. Animal Behaviour 42:326-327.

Boersma, P. 1993. Accurate short-term analysis of the fundamental frequency and the harmonics-to-noise ratio of a sampled sound. Proceedings of the Institute of Phonetic Sciences 17:97-110.

Braza, F., and C. San Josè. 1988. An analysis of mother-young behaviour of fallow deer during lactation period. Behavioural Processes 17:93-106.

Caro, T. M. 2005. Antipredator defenses in birds and mammals. University of Chicago Press, Chicago.

Charrier, I., N. Mathevon, and P. Jouventin. 2001. Mother's voice recognition in seal pups. Nature 412:873.

- 2002. How does a fur seal mother recognize the voice of her pup? an experimental study of Arctocephalus tropicalis. Journal of Experimental Biology 205:603-622.

Ekvall, K. 1998. Effects of social organization, age and aggressive behaviour on allosuckling in wild fallow deer. Animal Behaviour 56:695-703.

Engqvist, L. 2005. The mistreatment of covariate interaction terms in linear model analyses of behavioural and evolutionary ecology studies. Animal Behaviour 70:967-971.

Espmark, Y. 1971. Individual recognition by voice in reindeer mother-young relationship. Behaviour 40:295-301.

- 1974. Individual characteristics in the calls of reindeer calves. Behaviour 54:50-59.

Fisher, D. O., S. P. Blomberg, and I. P. F. Owens. 2002. Convergent 
maternal care strategies in ungulates and macropods. Evolution 56:167-176.

Fitch, W. T. 1997. Vocal tract length and formant frequency dispersion correlate with body size in rhesus macaques. Journal of the Acoustical Society of America 102:1213-1222.

Gilbert, B. K. 1968. Development of social behaviour in fallow deer (Dama dama). Zeitschrift für Tierpsychologie 25:867-876.

Gittleman, J. L., and S. D. Thompson. 1988. Energy allocation in mammalian reproduction. American Zoologist 28:863-875.

Insley, S. J. 2000. Long-term vocal recognition in the northern fur seal. Nature 406:404-405.

. 2001. Mother-offspring vocal recognition in northern fur seals is mutual but asymmetrical. Animal Behaviour 61:129-137.

Jouventin, P., and T. Aubin. 2002. Acoustic systems are adapted to breeding ecologies: individual recognition in nesting penguins. Animal Behaviour 64:747-757.

Kroodsma, D. E., B. E. Byers, E. Goodale, S. Johnson, and W. Liu. 2001. Pseudoreplication in playback experiments, revisited a decade later. Animal Behaviour 67:1029-1033.

McElligott, A. G., M. Birrer, and E. Vannoni. 2006. Retraction of the mobile descended larynx during groaning enables fallow bucks (Dama dama) to lower their formant frequencies. Journal of Zoology (London). doi:10.1111/j.1469-7998.2006.00144.x.

McGregor, P. K., C. K. Catchpole, T. Dabelsteen, J. B. Falls, L. Fusani, H. C. Gerhardt, F. Gilbert, et al. 1992. Design and interpretation of playback. Pages 1-9 in P. K. McGregor, ed. Playback and studies of animal communication. Plenum, New York.

Pélabon, C., N. G. Yoccoz, Y. Ropert-Coudert, M. Caron, and V. Péreira. 1998. Suckling and allosuckling in captive fallow deer (Dama dama, Cervidae). Ethology 104:75-86.

Pinheiro, J. C., D. Bates, S. Debroy, and D. Sarkar. 2004. nlme: linear and nonlinear mixed effects models. R package version 3.1-53.

Pond, C. M. 1977. The significance of lactation in the evolution of mammals. Evolution 31:177-199.

Press, W. H., W. T. Teukolsky, W. T. Vetterling, and B. P. Flannery. 1992. Numerical recipes in C: the art of scientific computing. Cambridge University Press, Cambridge.

R Development Core Team. 2004. R: a language and environment for statistical computing. R Foundation for Statistical Computing, Vienna. http://www.R-project.org.

Reby, D., and K. McComb. 2003. Anatomical constraints generate honesty: acoustic cues to age and weight in the roars of red deer stags. Animal Behaviour 65:519-530.

Roulin, A. 2002. Why do lactating females nurse alien offspring? a review of hypotheses and empirical evidence. Animal Behaviour 63:201-208.

Ruiz-Miranda, C. R., M. D. Szymanski, and J. W. Ingals. 1993. Physical characteristics of the vocalizations of domestic goat does Capra hircus in response to their offspring's cries. Bioacoustics 5:99-116.

Searby, A., and P. Jouventin. 2003. Mother-lamb acoustic recognition in sheep: a frequency coding. Proceedings of the Royal Society B: Biological Sciences 270:1765-1771.

Shillito-Walser, E., P. Hague, and E. Walters. 1981. Vocal recognition of recorded lambs' voices by ewes of three breeds of sheep. Behaviour 78:260-271.

Titze, I. R. 1994. Principles of voice production. Prentice Hall, Englewood Cliffs, NJ.

Trillmich, F. 1996. Parental investment in pinnipeds. Advances in the Study of Behaviour 25:533-577.

Trivers, R. L. 1972. Parental investment and sexual selection. Pages 136-179 in B. Campbell, ed. Sexual selection and the descent of man. Aldine, Chicago.

Vaňková, D., L. Bartoš, and J. Málek. 1997. The role of vocalization in the communication between red deer hinds and calves. Ethology 103:795-808.

Vannoni, E., M. V. G. Torriani, and A. G. McElligott. 2005. Acoustic signalling in cervids: a methodological approach for measuring vocal communication in fallow deer. Cognition, Brain, Behavior 9:551-565.

Venables, W. N., and B. D. Ripley. 2002. Modern applied statistics with S. 4th ed. Springer, New York.

Wiley, R. 2003. Is there an ideal behavioural experiment? Animal Behaviour 66:585-588.

Associate Editor: Tim Coulson

Editor: Jonathan B. Losos 